\title{
A critical appraisal of antihyperglycemic and cardioprotective activities of liraglutide: A glucagon-like peptide-1 analog
}

\section{Sayed Aliul Hasan Abdi, ${ }^{1,2}$, Md Shamshir Alam ${ }^{2,5}$, Najmi Abul Kalam², Churi Shobha', Ahmed Shafique ${ }^{2}$, Ali Maksood ${ }^{3,4}$}

${ }^{1}$ Department of Clinical Pharmacy, Jagadguru Sri Shivarathreeshwara College of Pharmacy, Jagadguru Sri Shivarathreeshwara Univesity, Mysore, Karnataka, ${ }^{2}$ Departments of Pharmacology, and ${ }^{3}$ Pharmacognosy and Phytochemistry, Jamia Hamdard, Hamdard University, New Delhi, India, ${ }^{4}$ Department of Pharmacognosy, College of Pharmacy, Jazan University, Jazan Province, ${ }^{5}$ Department of Clinical Pharmacy College of Pharmacy, Unaizah Qassim University, Kingdom of Saudi Arabia

Address for the Correspondence: Dr. Abul Kalam Najmi, Department of Pharmacology, Jamia Hamdard,

New Delhi - 110 062, India.

E-mail: aknajmi@hotmail.com

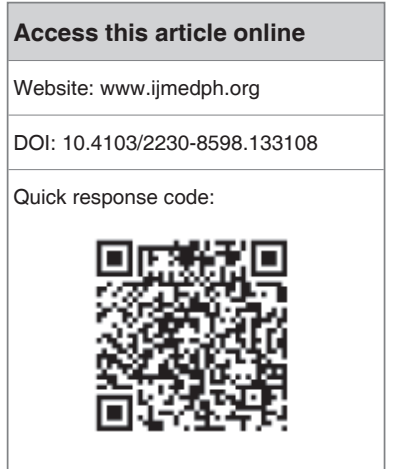

Diabetes is leading cause for cardiovascular complication, drugs having cardioprotective and antihyperglycemic actions are constantly in search. Oral glucose elicits a three to four times higher peak insulin response compared with an equivalent dose of glucose, if infused intravenously. This is due to the reasons behind, the oral glucose causes a secretion of gut hormones, mainly the glucagon-like peptide- 1 (GLP-1) and glucose-dependent insulinotropic polypeptide (GIP) which enhance the glucose-induced insulin release. In patients with type 2 diabetes mellitus (type 2 DM), glucose-induced insulin release is unsatisfactory or absent. Because of this type 2 DM patients are unable to adjust their insulin secretion as per the need exist. GLP-1 secretion (but not GIP secretion) is diminished in patients with type 2 diabetes. However, when the GLP-1 and GIP agonist are administered in patients with type 2 diabetes, they elicit insulin secretion resulting in lowering of blood glucose level. In addition to its insulin stimulatory effect, GLP-1 agonist also induces cardioprotective effects. It increases nuclear respiratory factor-2 (Nrf2) and heamoxigenase-1 (Ho-1) in cell which have antioxidant and cardioprotective property. GLP-1 maintains islets integrity and reduces apoptotic cell death of human islet cells in culture. Improved understanding of the mechanism of action and clinical effects of incretin-based therapies would be useful in advancement of its appropriate use in clinical practices.

Key words: Diabetes, GIP, glucagon-like peptide, nuclear respiratory factor-2, liraglutide

\section{INTRODUCTION}

Oral glucose load enhances the release of insulin than the similar quantity if administered intravenously and a difference of $40 \%-60 \%$ in the area- under-the curve of the insulin time concentration graph is registered. This difference is known as "incretin effect" which enhances the availability of insulin and decreases blood glucose. ${ }^{[1]}$ Owing to this effect, liraglutide GLP analogue has been approved by Food and Drug Administration for treatment of type 2 DM. ${ }^{[2]}$

Liraglutide is substituted product in the native hormone glucagon-like peptide-1 (GLP-1) obtained by the substitution of Lys 34 to Arg and by addition of a C16 fatty acid at $26^{\text {th }}$ position using an a glutamic acid spacer. Due to substitution of only one amino acid, liraglutide shares homology with native hormone native GLP-1. Since there is only one amino acid replacement, the resultant molecule shares 97\% (36/37 amino acids) sequence identity with native human GLP-1. In contrast to this, exenatide that was originally identified as a derivative of Gila monster (Heloderma suspectum) venom, shares only $53 \%$ sequence identity with native GLP-1. ${ }^{[3,4]}$ The aim of this review is to compile the antidiabetic and cardioprotective mechanism of liraglutide [Figure 1, adapted from Russell 2009].

\section{PHYSIOLOGY}

The incretins are the peptide hormones and the peptides are short polymers formed by the linking, in a defined order, of $\alpha$-amino acids. In humanGLP-1 and glucose-dependent insulinotropic polypeptide (GIP), the uppermost incretins which are secreted into circulation immediately after eating. GLP-1 and GIP are usually secreted by $\mathrm{L}$ and $\mathrm{K}$ cells subsequently, ( $\mathrm{L}$ cell located in the ileum and colon while K cell located in Duodenum).$^{[6-11]}$ 
Both incretins produce hormonal effects on multiple organs, important ones are the endocrine pancreas, gut, and the brain. Their most frequent effect is the regulation of energy homeostasis. Both, GIP and GLP-1 influence their actions by binding with specific receptors. The GIP receptors $(\mathrm{GIPR})^{[12,13]}$ and GLP-1 receptors (GLP-1R) ${ }^{[14,15]}$ belong to $G$ protein coupled receptor family and they stimulate insulin secretion in a glucose-dependent manner, delay gastric emptying, and suppress appetite. ${ }^{[16]}$ Aggregation of these effects plays an important role in glucose homeostasis, specifically in the control of postprandial glucose. ${ }^{[16]}$ Subsequent studies show that incretins improve glucose sensitivity of pancreatic $\beta$ cell and, promote pancreatic $\beta$ cell proliferation, and reduce $\beta$ cell cardiac cell apoptosis. ${ }^{[6,7]}$

The incretins act through G-protein-coupled receptors, the GLP-1 receptor, which is predominant in pancreatic islet and $\beta$ cells, heart, central nervous system, kidney, lungs, and gastrointestinal tract. The GIP receptor, however, is highly observable in the pancreatic islet $\beta$ cells and less in the central nervous system and in adipose tissues $^{[6,16,17]}$ [Figure 2].

The response of incretin to a meal lasts approximately 2-3 hours even short half-life (1-2 $\mathrm{min}$ ) because there is ongoing production of incretins due to presence of nutrients in the gut. Dipeptidylpeptidase-4 (DPP4), an enzyme that is ubiquitously expressed in endothelial cells, is responsible for incretin metabolism. ${ }^{[7,17]}$

\section{PHARMACOLOGY}

\section{Mechanism of action}

Liragluatide contains fatty acid molecule at $26^{\text {th }}$ position that have affinity to bind with albumin and enhances the life of molecule than endogenous GLP-1 molecule which is degraded easily with DPP4 and creates minimum insulin secretion. GLP-1 receptors are predominant in pancreatic alpha and beta cells, the central and peripheral nervous systems, the heart, lung, and the gastrointestinal tract where they enhance insulin release. GIP and GLP-1 are secreted once after the food ingestion and leads to the glucose-dependent insulin secretion. Once released, GIP and GLP-1 are subjected to degradation by DPP4 on lymphocytes and on endothelial cells of blood vessels. Due to presence of C16 fatty acid liraglutide action

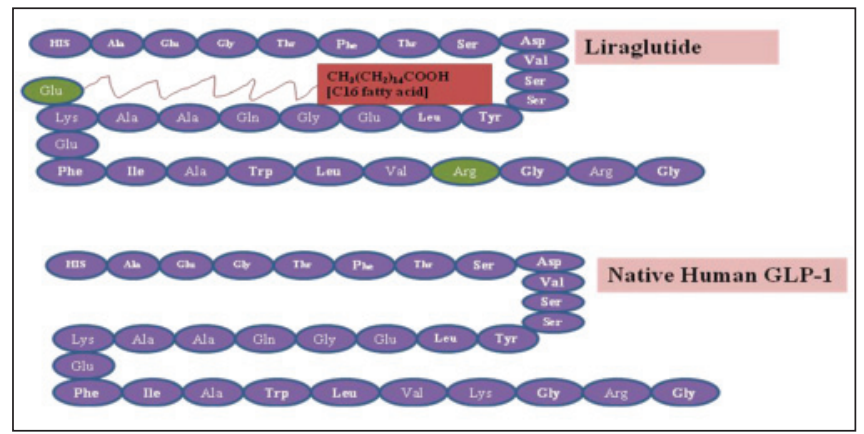

Figure 1: Chemical structure of native glucagon-like peptide-1 (GLP-1) and GLP-1 receptor agonists liraglutide (Image edited from reference ${ }^{[4]}$ ) is prolonged and the binding of incretin ligands or agonist to the incretin receptors results in production of cAMP via adenylyl cyclase (AC) activation, which leads to elevation of intracellular calcium levels the enhance in intracellular calcium concentrations tend to fusion of insulin-containing vesicles to the plasma membrane and exocytosis of insulin from $\beta$ cell [Figure 3]. ${ }^{[7,18,19]}$

\section{Pharmacodynamic drug interactions}

According to European Medical agency, liraglutide shows synergistic effects in combination with the $\gamma$-peroxisome proliferator-activated receptor (PPAR $\gamma$ ) agonist pioglitazone, and also with the sulfonylurea glipizide. ${ }^{[20,21]}$

\section{PHARMACOKINETICS}

In isotonic solution, the liraglutide should be administered subcutaneously. According to European Medical agency the peak concentration of liraglutide approaches between 3 and $9 \mathrm{~h}$ and the half-life is $13 \mathrm{~h}$ after single administration. However, endogenous administration of GLP-1 has the half-life of approximately 2 min due to DPP4 degradation. Presence of fatty acid chain in liraglutide molecule forms heaptamers at injection site depot and allows reversible binding to serum albumin may probably be responsible for delayed absorption of liraglutide and resistance to metabolism by DPP4, and reduces renal clearance. For such extended mode of action once daily dose is sufficient. ${ }^{[5,20-22]}$

\section{ADVANTAGES}

- Hypoglycemia: It was found that incretin mimetics have low risk of hypoglycemia than other class of antidiabetic drugs due to the induction of insulin secretion in a glucose-dependent way.

- Effect on beta-cell health: Prevent cellular apoptosis and maintain $\beta$ cell morphology.

- $\quad$ Effect on postprandial hyperglycemia: Incretins can maintain on this crucial parameter by direct inhibition of the glucagon release and enhanced insulin release. ${ }^{[5,20-22]}$

\section{CARDIOPROTECTIVE MECHANISM OF LIRAGLUTIDE}

Caspase (cysteine aspartic protease) have important roles in apoptosis. Protease is an enzyme which is responsible for proteolysis.

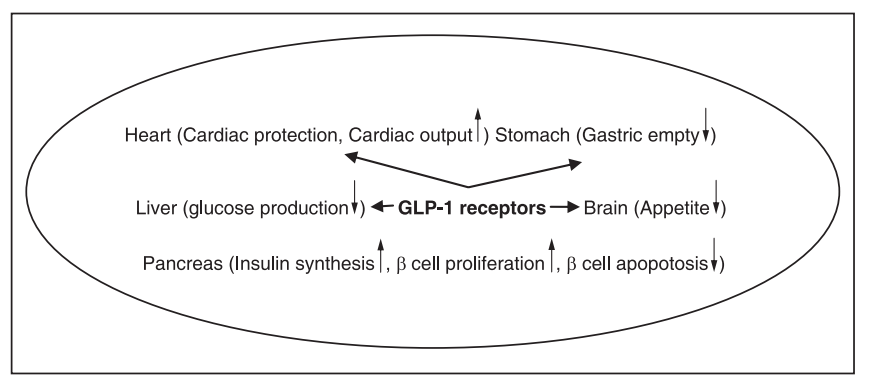

Figure 2: Glucagon-like peptide-1 receptor and their function 
Liraglutide may modulate gene function during apoptosis and exhibits cardioprotective actions by activating cardioprotective signaling pathways in the heart. Further, it inhibits the enzyme caspase which play significant role in the conversion of stimulus to death receptors for apoptotic signals. ${ }^{[23]}$ Caspase can be categorized as inhibitor and effector $(8,9,10,2)$ and $(3,7,6)$ subsequently. ${ }^{[24]}$ Caspase initiator gets activated after binding with specific oligomeric adaptor protein and effector activation is brought about due to initiator caspase activation through proteolytic cleavage followed by effector caspases which proteolytically degrade a host of intracellular protein to progress cell death. ${ }^{[2]}$ Liraglutide inhibits the caspase-3 which usually occurs at high level during doxorubicin-induced cardiotoxicity and coronary artery occlusion in mice. ${ }^{[23]}$ Marre et al., found a higher level of caspase- 3 in these mice which plays an important role in cell apoptosis it was also found a declined concentration of caspase- 3 when coronary artery occludes diabetic mice was treated with liraglutide. ${ }^{[23]}$

Liraglutide acts on GLP-1R modulate adenylcylase consequently phosphatidylinositol 3-kinases (Pi3k) become activated. ${ }^{[23]}$ This activation leads to phosphorylation of Akt (protein kinase-B). Akt is responsible for autophosphorylation of $\mathrm{Bcl} 2$ associated death promoter (BAD). Phosphorylation of BAD results in inhibition of cell apoptosis which finally increases the transcription of antioxidants and cardioprotective factors such as peroxisome proliferator activated receptor (PPAR $\beta \alpha$ ), nuclear respiratory factor-2 (Nrf2), and heamoxigenase-1(Ho-1) ${ }^{[23,24]}$ [Figure 4].

\section{DOSAGE AND ADMINISTRATION}

Liraglutide can be injected through abdomen subcutaneously or through thigh or upper arm at any time in a day independent of the time and meal adherence. The $0.6 \mathrm{mg}$ dose should be started as per recommendations and then it may be titrated 1.2 or $1.8 \mathrm{mg}$ once daily with respect to the desired $\mathrm{HbA1c}$ goal. While initiating

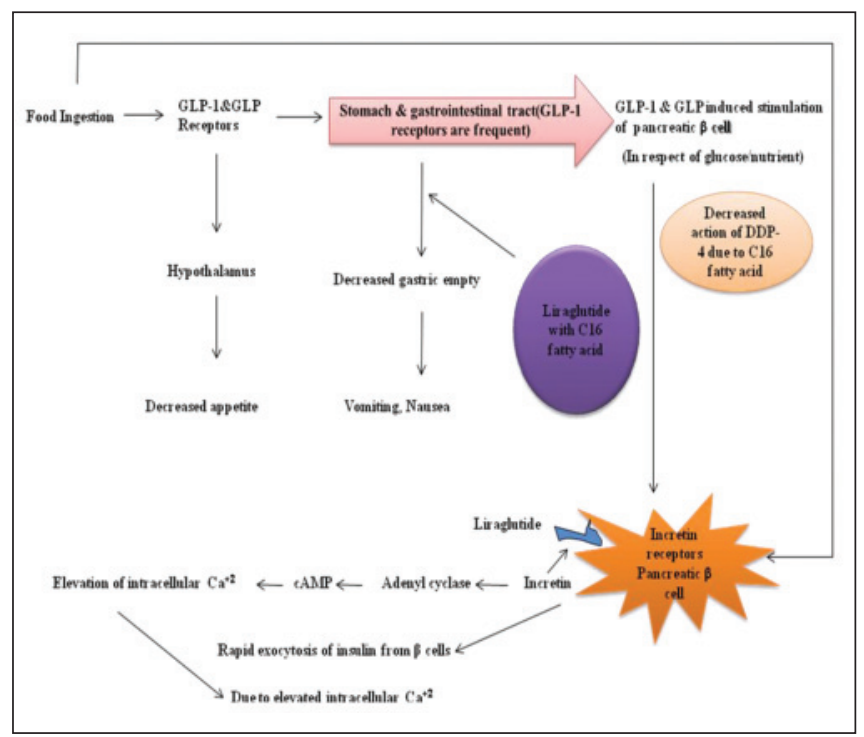

Figure 3: Schematic representation of incretin secretion and action the treatment with liraglutide, a dose reduction of concomitantly administered insulin secretagogues (such as sulfonylureas) should be considered to reduce the risk of hypoglycemia. ${ }^{[22,26]}$

\section{ADVERSE EFFECTS ASSOCIATED WITH LIRAGLUTIDE}

\section{Gastrointestinal and hypoglycemia}

Gastrointestinal problem such as diarrhea, nausea, dyspepsia, constipation, and nervous system disorders such as headache and dizziness, particularly during the first 4 weeks are the most predictable adverse events that occurred during the clinical trial on the effects and action of liraglutide in diabetes (LEAD-1). The occurrence of nausea was highest $(10.5 \%)$, whereas the hypoglycemia major and hypoglycemia minor were found to be at $0 \%$ and $9.2 \%$ subsequently in LEAD-1clinical trial. Hypoglycemic episode required third party assistance was considered as hypoglycemia major and self-treated were considered as hypoglycemia minor. ${ }^{[25]}$

\section{Pancreatitis}

Pancreatitis was reported in the cohort study conducted by Noel et al., whereas diabetes has prevalence to develop pancreatitis. Therefore, it is difficult to establish that liraglutide is the real culprit in pancreatitis. ${ }^{[26,29]}$

\section{Immunogenicity}

Treatment with liraglutide may probably be responsible for generation of antiliraglutide antibody formation such as the antirifampin antibody, ${ }^{[31]}$ which has been reported in phase 3 clinical trial in $4 \%-13 \%$ patients. ${ }^{[27,31]}$

\section{Lipohypertrophy}

Long-term insulin therapy is main cause of lipohypertrophy. ${ }^{[30]}$ However, incidence of lipohypertrophy with liraglutide is not

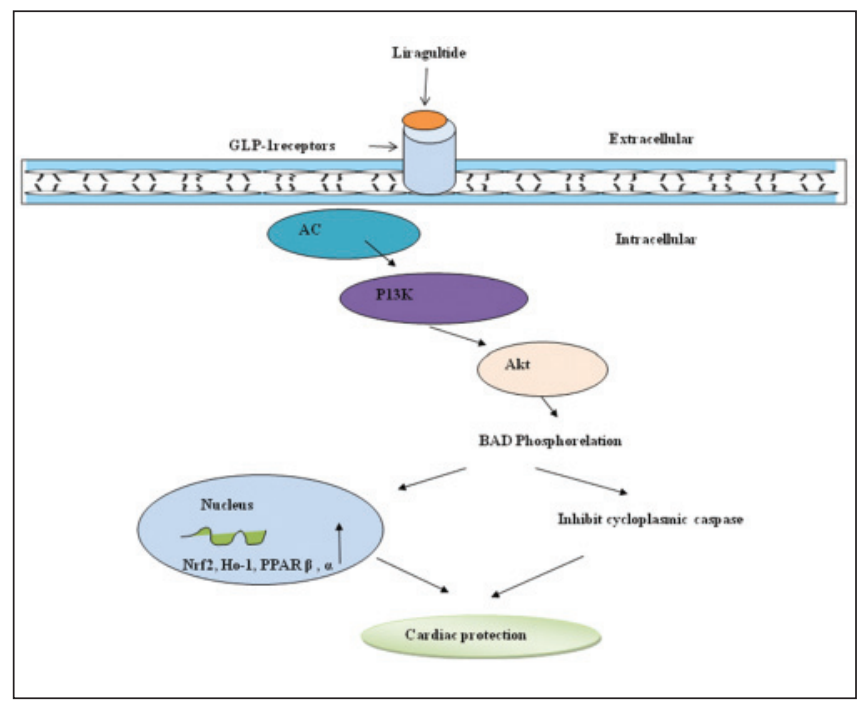

Figure 4: A schematic representation of cardioprotective signaling pathways of liraglutide 
reported in the clinical trials conducted on diabetic subjects; however, the urticarial reactions were not ruled out. ${ }^{[32]}$

\section{PATIENT COUNSELLING INFORMATION}

\section{Risk of thyroid c-cell tumors}

Patients counseling should be done for thyroid tumors symptoms such as a lump in the neck, hoarseness, dysphagia, or dyspnea. ${ }^{[5,20,32]}$

\section{Pancreatitis}

Patients should be informed regarding the symptoms of pancreatitis which may lead to severe abdominal pain with vomiting. Patients should be advised to discontinue liraglutide swiftly in case of persistent severe abdominal pain and should consult the concerned physician. ${ }^{[20,32]}$

\section{Instructions}

Patients should be counseled that nausea is most common with the initiation of liraglutide therapy while starting liraglutide initially, but decreases over time in the majority of patients and does not typically require discontinuation of liraglutide. Patients should be instructed to inform their doctor or pharmacist if they develop any unusual symptom or if any known symptom persists or worsens. ${ }^{[1,20,32]}$

\section{CONCLUSION}

Liraglutide-based therapies are relatively new options for the treatment of patients with type 2 diabetes. These agents have low risk associated with hypoglycemia and weight gain in contrast to those drugs which are generally used in the treatment of type-2 diabetes mellitus and shows cardioprotective effect. The monotherapy of GLP-1 receptor agonists and DPP-4 inhibitors have a low risk of hypoglycemia because they stimulate insulin secretion in a glucose-dependent manner. Also, the DPP-4 inhibitors generally do not have any effect on weight, while GLP-1 receptor agonists may cause weight loss. Therapies that cause weight loss may enhance insulin sensitivity and, therefore, have significant benefit in the treatment of type 2 diabetes. GLP-1 receptor agonists may be useful in those patients who are overweight and have risks for developing hypoglycemia and cardiovascular complication. However, the diligent postmarketing surveillance is required to confirm the safety and efficacy of these promising agents, and to determine risk factors associated with the development of the adverse drug reactions.

\section{REFERENCES}

1. Triplitt CL. New technologies and therapies in the management of diabetes. Am J Manag Care 2007;13:S47-54.

2. U. S. department of health \& human services. [Online]. Available from: URL: http://www.fda.gov/Drugs/DrugSafety [Last cited on 2010 Jan 23].

3. Lovshin JA, Drucker DJ. Incretin-based therapies for type 2 diabetes mellitus. Nat Rev Endocrinol 2009;5:262-9.

4. Russell-Jones D. Molecular, pharmacological and clinical aspects of liraglutide a once-daily human GLP-1 analogue. Mol Cell Endocrinol 2009;297:137-40
5. Neumiller JJ. Differential chemistry (structure) mechanism of action and pharmacology of GLP-1 receptor agonists and DPP-4 inhibitors. J Am Pharm Assoc (2003) 2009;49:S16-29.

6. Prins JB. Incretin mimetics and enhancers mechanisms of action. Aust Prescr 2008;31:102-4.

7. Noel RA, Braun DK, Patterson RE, Bloomgren GL. Increased risk of acute pancreatitis and biliary disease observed in patients with type 2 diabetes: A retrospective cohort study. Diabetes Care 2009;32:834-8.

8. Nauck M, Stockmann F, Ebert R, Creutzfeldt W. Reduced incretin effect in type 2 (non-insulin-dependent) diabetes. Diabetologia 1986;29:46-52.

9. Drucker DJ, Nauck MA. The incretin system: Glucagon-like peptide-1 receptor agonists and dipeptidyl peptidase- 4 inhibitors in type 2 diabetes. Lancet 2006;368:1696-705.

10. Drucker DJ. The biology of incretin hormones. Cell Metab 2006;3:153-65.

11. Nathan DM, Buse JB, Davidson MB, Ferrannini E, Holman RR, Sherwin R, et al. Medical management of hyperglycemia in type 2 diabetes: A consensus algorithm for the initiation and adjustment of therapy: A consensus statement of the American Diabetes Association and the European Association for the Study of Diabetes. Diabetes Care 2009;32:193-203.

12. Gremlich S, Porret A, Hani EH, Cherif D, Vionnet D, Froguel P, et al. Cloning, functional expression, and chromosomal localization of the human pancreatic islet glucose-dependent insulinotropic polypeptide receptor. Diabetes 1995;44:1202-8.

13. Yasuda K, Inagaki N, Yamada Y, Kubota A, Seino S, Seino Y. Hamster gastric inhibitory polypeptide receptor expressed in pancreatic islets and clonal insulin-secreting cells: Its structure and functional properties. Biochem Biophys Res Commun 1994;205:1556-62.

14. Dillon JS, Tanizawa Y, Wheeler MB, Leng XH, Ligon BB, Rabin DU, et al. Cloning and functional expression of the human glucagon-like peptide-1 (GLP-1) receptor. Endocrinology 1993;133:1907-10.

15. Thorens B. Expression cloning of the pancreatic beta cell receptor for the gluco-incretin hormone glucagon-like peptide 1. Proc Natl Acad Sci U S A 1992;89:8641-5.

16. Juhl $C B$, Hollingdal M, Sturis J, Jakobsen G, Agerso H, Veldhuis J, et al. Bedtime administration of NN2211 a long-acting GLP-1 derivative substantially reduces fasting and postprandial glycemia in type 2 diabetes. Diabetes 2002;51:424-9.

17. National Institute for Health and Clinical Excellence UK. [Online]. Available from: URL: http://www.nice.org.uk/nicemedia/pdf/cg87shortguideline.pdf [Last cited on 2009 May 29].

18. Kim W, Egan JM. The role of incretins in glucose homeostasis and diabetes treatment. Pharmacol Rev 2008;60:470-512.

19. Victoza (liraglutide), product information. Princeton, N.J.: Novo Nordisk, Inc; 2010.

20. Agerso $H$, Jensen LB, Elbrond B, Rolan P, Zdravkovic M. The pharmacokinetics, pharmacodynamics, Safety and tolerability of NN2211, a new long- acting GLP-1 derivative in healthy men. Diabetologia 2002;45:195-202.

21. Assessment report for Liraglutide European medicines agency. [Online]. Available from: URL: http://www.emea.europa.eu [Last cited on 2009 May 15].

22. Liraglutide news archive. [Online]. Available from: URL:http//www. novonordisk.com/press/liraglutide-press-room/liraglutide-news.asp [Last cited on 2010 June 22].

23. Marre M, Shaw J, Brandle M, Bebakar WM, Kamaruddin NA, Strand $\mathrm{J}$, et al. LEAD-1 SU study group. Liraglutide a once-daily human GLP1 analogue added to a sulphonylurea over 26 weeks produces greater improvements in glycaemic and weight control compared with adding rosiglitazone or placebo in subjects with Type 2 diabetes (LEAD-1 SU) Diabet Med 2009;26:268-78.

24. Nauck M, Frid A, Hermansen K, Shah NS, Tankova T, Mitha IH, et al. LEAD-2 Study Group. Efficacy and safety comparison of liraglutide, glimepiride, and placebo, all in combination with metformin in type 2 diabetes: The LEAD (liraglutide effect and action in diabetes)-2 study. Diabetes Care 2009;32:84-90.

25. Garber A, Henry R, Ratner R, Garcia-Hernandez PA, RodriguezPattzi H, Olvera-Alvarez I, et al. LEAD-3 (Mono) Study Group. Liraglutide versus glimepiride monotherapy for type 2 diabetes (LEAD-3 Mono): A randomized 52-week phase III double-blind parallel-treatment trial. Lancet 2009;373:473-81. 
26. Bain SC, Stephens JW. Exenatide and pancreatitis: An update. Expert Opin Drug Saf 2008;7:643-4.

27. Kakaiya RM, Dehertogh D, Walker FJ, Cummings E, Uzdejczyk M. Rifampin-induced immune thrombocytopenia. A case report. Vox Sang 1989;57:185-7.

28. Madsbad S, Schmitz O, Ranstam J, Jakobsen G, Matthews DR; NN22111310 International Study Group. Improved glycemic control with no weight increase in patients with type 2 diabetes after once-daily treatment with the long-acting glucagon-like peptide 1 analog liraglutide (NN2211): A 12-week double-blind, randomized, controlled trial. Diabetes Care 2004;27:1335-42

29. Zinman B, Gerich J, Buse JB, Lewin A, Schwartz S, Raskin P, et al. LEAD-4 Study Investigators. Efficacy and safety of the human glucagonlike peptide-1 analog liraglutide in combination with metformin and thiazolidinedione in patients with type 2 diabetes (LEAD-4Met+TZD). Diabetes Care 2009;32:1224-30.

30. Hauner H, Stockamp B, Haastert B. Prevalence of lipohypertrophy in insulin-treated diabetic patients and predisposing factors. Exp Clin Endocrinol Diabetes 1996;104:106-10.

31. Feinglos MN, Saad MF, Pi-Sunyer FX, An B, Santiago O; Liraglutide Dose-Response Study Group. Effects of liraglutide (NN2211) a longacting GLP-1 analogue on glycaemic control and bodyweight in subjects with Type 2 diabetes. Diabet Med 2005;22:1016-23.

32. Liraglutide news archive. [Online]. Available from: URL: http//www. novonordisk.com/press/liraglutide-press-room/liraglutide-news.asp. [Last cited on 2010 April 29].

How to cite this article: Abdi SH, Alam MS, Kalam NA, Shobha C, Shafique A, Maksood A. A critical appraisal of antihyperglycemic and cardioprotective activities of liraglutide: A glucagon-like peptide-1 analog. Int J Med Public Health 2014;4:141-5.

Source of Support: Nil, Conflict of Interest: None declared. 